\title{
Assessment of the biomass related indoor air pollution in Kwale district in Kenya using short term monitoring
}

\author{
Marek Majdan ${ }^{1}$, Miroslav Svaro $^{1}$, Jan Bodo ${ }^{2}$, Mark Taylor ${ }^{1}$, Redempta Malinda Muendo ${ }^{3}$
}

\author{
1. Trnava University, Faculty of Health Sciences and Social Work, Department of Public Health, Univerzitne \\ namestie 1, 91701, Trnava, Slovakia \\ 2. Trnava University, Faculty of Health Sciences and Social Work, Department of Tropical Public Health \\ and Development Studies, Univerzitne namestie 1, 91701, Trnava, Slovakia \\ 3. County Public Health Officer, Kwale County, Kenya
}

\begin{abstract}
Background: Indoor air pollution remains an important health problem in some countries. Although research data on this issue is available, routine monitoring in affected areas is limited. The aims of this study were to quantify exposure to biomass-related indoor air pollution; assess the respiratory health of subjects; and explore the feasibility of routine monitoring in Kwale district, Kenya.

Methods:We sampled 125 rural houses using short-term monitoring for levels of $\mathrm{CO}, \mathrm{CO}_{2}$ and TSP. Additional exposure information was obtained using a checklist. Respiratory health was also assessed using a questionnaire, and electronic spirometer in 172 inhabitants.

Results: The overall median levels of CO in the sampled houses on all study sites ranged from 5.9 (IQR 3-14.5) to 10 (5.521.2) $\mathrm{mg} / \mathrm{m} 3$, levels of $\mathrm{CO}_{2}$ ranged from 774 (IQR 724-846) to 839 (IQR 749-961) $\mathrm{mg} / \mathrm{m} 3$ ) and the levels of TSP ranged from 295 (IQR 79-853 to 1384 (IQR 557-3110) $\mu \mathrm{g} / \mathrm{m}^{3}$ which indicates that safe levels recommended by WHO and USEPA could be exceeded. Relatively high incidences of respiratory illness or symptoms were reported and the spirometry readings suggested impaired lung function in over $80 \%$ of respondents.

Conclusion: Our results quantify that the use of biomass fuel can give rise to high levels of indoor air pollution. Given that poor lung function contributes to public health problems in rural regions of East Africa, such as Kwale in Kenya, our findings create grounds for more detailed investigations of the problem and may provide motivation for community based interventions.
\end{abstract}

Keywords: Indoor air quality, rural communities, environmental exposures, environmental monitoring, respiratory tract disease, public health

DOI: http://dx.doi.org/10.4314/ahs.v15i3.35

Cite as: Majdan M, Svaro M, Bodo J, Taylor M, Muendo RM. Assessment of the biomass related indoor air pollution in Kwale district in Kenya using short term monitoring. Afri Health Sci. 2015;15(3):972-81. doi: bttp:/ / dx.doi.org/10.4314/ abs.v15i3.35

\section{Introduction}

Indoor air pollution has been identified as a public health problem requiring greatly increased efforts in research and policy making ${ }^{1-3}$. It has been estimated that $90 \%$ of rural households in developing countries

\author{
Corresponding author: \\ Marek Majdan \\ Trnava University, Faculty of Health Sciences \\ and Social Work \\ Department of Public Health \\ Univerzitne namestie 1, 91701 Trnava, Slovakia \\ Tel:+421905951786, \\ fax:+421335939555, \\ email:mmajdan@truni.sk, \\ marekmajdan@gmail.com
}

rely on biomass as the primary household fuel ${ }^{4}$ and in some parts of the world the reliance on biomass is increasing $^{2,5}$. When used in open fire or simple small-scale devices, biomass fuels emit large amounts of hazardous airborne pollutants such as respirable particulates, carbon monoxide $(\mathrm{CO})^{6}$, and numerous hydrocarbons and oxygenated organics as well as chlorinated organic compounds, many of which have been linked to deleterious effects on health, in vitro and/or in vivo?

The magnitude of the problem of exposure to pollutants from biomass use is a function of the pollution levels and the time the persons spend indoors ${ }^{8}$. Because of their traditional local roles in activities such as cooking, women seem to suffer the highest exposure and subsequently health impacts, and young children who usually accompany their mothers are also of concern. ${ }^{5,89}$. Exposure to pollutants from biomass has been linked by a 
number of studies to respiratory infections (upper and lower respiratory tract infection, chronic obstructive pulmonary disease -COPD, tuberculosis, lung cancer, asthma) and non-respiratory illness (low birth weight and infant mortality, cardiovascular disease, cataracts, nasopharyngeal and laryngeal cancer) ${ }^{10-13}$.

Poverty appears to be the main barrier to adopting clean fuels, so the poorest communities are expected to continue using biomass ${ }^{2}$. To tackle the problem, large scale and systematic community interventions are needed ${ }^{7}$.

The aim of the study was to assess biomass related indoor air pollution, to estimate the exposure of women and children to hazardous emissions, and to assess the prevalence of related respiratory health symptoms, in a sample population drawn from Kwale district, Kenya - a prevailingly rural region where most of the households rely on biomass and open fire as a primary method for cooking.

\section{Methods}

\section{Study setting and population}

The study was conducted within the administrative boundaries of the Kwale district in the Coastal Province of Kenya. Rural households were recruited for the study in the vicinities of Magawani, Shimba Hills, Waa, Mwaluphamba and Lukore health dispensaries. No randomization process was applied. Houses were included in the study in consecutive order based on the consent of the owners after the aims of the study were explained by the assisting community health workers. No exclusion criteria were applied for the households. Respondents for the questionnaire interviews and spirometrical examinations were recruited from the residents of the houses. In all houses the person principally responsible for cooking was approached in the first place followed by other members of the families. Permanent living in one of the houses included in the study was the only inclusion criteria applied. No age or sex limitations were imposed.

\section{Exposure assessment}

Concentration of total suspended particles (TSP), CO and Carbondioxide (CO2) were measured in order to assess the exposure to biomass related pollutants in the indoor environment. TSP was measured using the Microdust Pro ${ }^{15}$ monitor produced by Casella Measurements, USA. The Direct Sense IAQ ${ }^{16}$ indoor air quality monitor produced by GrayWolf sensing solutions, USA was used to sample for levels of $\mathrm{CO}, \mathrm{CO}_{2}$, temperature and humidity. The sampling set allowed for real time logging.
The air sampling equipment was mounted on tripods and placed in the approximate position of the person sitting in her/his usual position during cooking, fire starting or food preparation. Both monitors were set to $\log$ the levels of monitored pollutants at intervals of 10 seconds. The total time of monitoring was at least 20 minutes.

\section{Respiratory health assessment}

To assess the respiratory health of inhabitants of the sampled houses a spirometrical examination and a questionnaire interview were conducted. The Amspir SP1019 portable set was used to perform spirometries. The quality of the process of spirometrical screening was assured through personal supervision of each examination by a trained and experienced physician on the team (JB). First, the procedure was practically demonstrated to each participant by the physician, with the help of a local representative of the Kwale Public Health Officer (all such assistants had been briefed on the procedure prior to the field work and were familiar with it). Then, the respondents were asked to perform a "training" examination (with the spirometer turned off) in order to verify that they understood the procedure. After that, they were asked to breathe into the spirometer according to instruction, and a measurement was recorded. In case this was not successful, repeated measurements were performed until the procedure was deemed to have been carried out correctly according to $\mathrm{JB}$, the expert physician. In case the individual failed to perform the examination correctly (after a maximum of three repetitions) he/she was not included in the sample. All correctly performed examinations were recorded on the memory card of the spirometer, and backedup to a laptop. The evaluation of the spirograms was done by the expert physician using specialized software provided by the manufacturer of the spirometer.

A simplified questionnaire was developed based on standardized respiratory health questionnaires (Questionnaire About Respiratory Diseases From the American Thoracic Society and the Division of Lung Diseases, National Heart, Lung and Blood Institute, USA - ATS-DLD-78 ${ }^{17}$ and the St. George respiratory questionnaire ${ }^{18}$ ). Pilot testing revealed problems of comprehension with the full standardized questionnaire, but a shorter, simplified version was more widely understood and completed. The simplified questionnaire was pilot tested for comprehension and finalized into the form that was used for the study after evaluating the pilot test. 


\section{Environmental and behavioural checklist (EBC)}

In order to obtain a detailed description of the sampled houses and of the behaviour of inhabitants a checklist was used. The information obtained this way included data on size of the house, construction material used, build style (presence of windows, type of roof, relation to other rooms in the house or other buildings), usual length of fire use each time, number of fires per day as well as personal behavioural information such as amount of time spent indoors while cooking.

\section{Data analysis}

First, all data was compared between the settlements. Levels of indoor pollutants were additionally compared between houses with burning fire (defined as fire with visible flames), kindling fire (defined as a fire without visible flames but still emitting smoke) or no fire burning (dead fire without flames or any visible smoke emission) at the time of monitoring. As central measures of continuous variables, medians with interquartile ranges were used. In categorical variables percentages were generated from frequency scores. The Kruskal-Wallis test was used to analyse differences between continuous variables, and the Chi-Square test or Fisher's exact test (in case of counts $<5$ ) were used as appropriate in testing differences in categorical variables. P-values of $<0.05$ were considered statistically significant. The $\mathrm{R}$ statistical software was used for all statistical analyses.

\section{Ethics approval}

The presented study was approved by the Ethics Committee of Trnava University, approval number VR13524. The study was conducted with a written approval of the Kwale district Public Health Office and the Kwale district Ministry of Public Health and Sanitation and in close cooperation with these authorities. Participation in the study was voluntary, and verbal consent was obtained from all participants after the study purpose and methods were explained to them.

\section{Results \\ Indoor air quality}

A total of 125 households were included in the study; their basic description is presented in Table 1. A large proportion of the houses had a kitchen in a stand alone building separate from the main house ( $\mathrm{N}=74,39 \%)$. One or two additional rooms were most common in cases where the kitchen was incorporated in the main building, usually having a separate entrance door. In cases where the living room or bedroom was connected to the kitchen this was through curtain-door or open ceiling in most cases. The living room was in the same room as the kitchen in 14 houses (11\%), and in 3 houses $(2 \%)$ the kitchen was in the same room as the bedroom. In at least three quarters of the cases the kitchens had no windows. The median kitchen room-volume was 16 cubic meters. The building material was uniformly mud and wood for the walls and palm leaves for the roof. No chimneys were observed in any of the houses.

Table 2 presents the main results of the indoor air monitoring. The median level of $\mathrm{CO}$ in all houses was 8.5 (IQR of $4-18.3) \mathrm{mg} / \mathrm{m}^{3}$ with the highest median of 10 (IQR 5.5-21.2) $\mathrm{mg} / \mathrm{m}^{3}$ in the village of Waa and the lowest median of 5.9 (IQR 3-14.5) $\mathrm{mg} / \mathrm{m}^{3}$ in Shimba Hills. The median of CO2 was 801 (740-917) $\mathrm{mg} / \mathrm{m}^{3}$ for all houses. The highest median of TSP was observed in the village of Waa and the lowest in Magawani. The total median was 550 (IQR 195-1,444) $\mu \mathrm{g} / \mathrm{m}^{3}$. 
Table 1: Description of the sampled houses by village

\begin{tabular}{|c|c|c|c|c|c|c|c|c|}
\hline & \multicolumn{2}{|l|}{ Lukore } & $\begin{array}{l}\text { Magawa } \\
\text { ni }\end{array}$ & $\begin{array}{l}\text { Mwalupha } \\
\text { mba }\end{array}$ & $\begin{array}{c}\text { Shimba } \\
\text { Hills }\end{array}$ & Waa & Total & \multirow{3}{*}{ P-value* } \\
\hline & $\mathbf{N}$ & $\%$ & $\mathbf{N} \%$ & $\mathbf{N} \quad \%$ & $\mathbf{N} \quad \%$ & $\%$ & $\%$ & \\
\hline Number of houses & 14 & 11 & 26 & 19 & 29 & 31 & 125 & \\
\hline \multicolumn{9}{|c|}{ Additional rooms in the same building } \\
\hline Isolated Kitchen & 10 & 10 & 42 & 26 & 11 & 27 & 47 & \multirow{4}{*}{0.051} \\
\hline One & 4 & 29 & 23 & 32 & 27 & 23 & 26 & \\
\hline Two & 0 & 0 & 19 & 26 & 8 & 12 & 25 & \\
\hline Three + & 0 & 0 & 16 & 16 & 23 & 10 & 14 & \\
\hline \multicolumn{9}{|c|}{ Kitchen and living room connection } \\
\hline Curtain door & 0 & 0 & 16 & 20 & 28 & 2 & 18 & \multirow{5}{*}{0.031} \\
\hline Door & 0 & 0 & 3 & 0 & 1 & 19 & 7 & \\
\hline Not joined & 14 & $\begin{array}{c}10 \\
0\end{array}$ & 69 & 60 & 16 & 17 & 78 & \\
\hline Open ceiling & 0 & 0 & 13 & 13 & 14 & 13 & 14 & \\
\hline Same room & 0 & 0 & 0 & 7 & 0 & 7 & 2 & \\
\hline \multicolumn{9}{|c|}{ Kitchen and living room connection } \\
\hline Curtain door & 0 & 0 & 3 & 42 & 29 & 10 & 22 & \multirow{5}{*}{$<0.001$} \\
\hline Door & 0 & 0 & 13 & 0 & 1 & 23 & 9 & \\
\hline Not joined & 13 & 93 & 1134 & 37 & 13 & 14 & 58 & \\
\hline Open ceiling & 1 & 7 & 28 & 1 & 11 & 23 & 21 & \\
\hline $\begin{array}{ll}\text { Same room } \\
\end{array}$ & 0 & 0 & 25 & 16 & 11 & 0 & 14 & \\
\hline \multicolumn{9}{|l|}{ Windows in kitchen } \\
\hline None & 11 & 79 & 27 & 17 & 23 & 23 & 101 & \multirow{3}{*}{0.912} \\
\hline One & 2 & 14 & 13 & 11 & 17 & 23 & 10 & \\
\hline Two & 1 & 7 & 3 & 0 & 1 & 1 & 3 & \\
\hline $\begin{array}{r}\text { Kitchen opening area } \\
\text { (square meter. Median. IQR) }\end{array}$ & $\begin{array}{c}0.49 \\
(0-1.40)\end{array}$ & & $\begin{array}{c}0 \\
(0-3.56)\end{array}$ & $\begin{array}{c}2.36 \\
(0-3.56)\end{array}$ & $\begin{array}{l}3.56 \\
(0-6.3)\end{array}$ & $\begin{array}{c}11.8 \\
(1.97-78.7)\end{array}$ & $\begin{array}{c}2.36 \\
(0-7.87)\end{array}$ & $<0.001$ \\
\hline $\begin{array}{r}\text { Kitchen floor area } \\
\text { (square meter. Median. IQR) }\end{array}$ & $\begin{array}{c}16 \\
(12-20)\end{array}$ & & $\begin{array}{c}7 \\
(4-10)\end{array}$ & $\begin{array}{c}9 \\
(6-12)\end{array}$ & $\begin{array}{c}6.5 \\
(3.8-10.5)\end{array}$ & $\begin{array}{c}5 \\
(4.8-8)\end{array}$ & $\begin{array}{c}7 \\
(5-12)\end{array}$ & 0.036 \\
\hline $\begin{array}{r}\text { Kitchen volume } \\
\text { (cubic meter. Median. IQR) }\end{array}$ & $\begin{array}{c}32 \\
(22.5-38)\end{array}$ & & $\begin{array}{c}20 \\
(8-24)\end{array}$ & $\begin{array}{c}18 \\
(12.8-27)\end{array}$ & $\begin{array}{c}15 \\
(9.3-31.5)\end{array}$ & $\begin{array}{c}10 \\
(9.8-16)\end{array}$ & $\begin{array}{c}16 \\
(10-25.5)\end{array}$ & 0.017 \\
\hline
\end{tabular}

$\mathrm{IQR}=$ inter quartile range

*P-values refer to the difference between the five compared villages. tested with Chi-squared test for categorical variables and with the Kruskal-Wlis test for medians

Table 2: Levels of indoor pollutants in the sampled houses by village

\begin{tabular}{|c|c|c|c|c|c|c|c|}
\hline & Lukore & Magawani & Mwaluphamba & $\begin{array}{c}\text { Shimba } \\
\text { Hills }\end{array}$ & Waa & Total & $P$ value* \\
\hline Number of houses & $14(11 \%)$ & $32(26 \%)$ & $19(15 \%)$ & $29(23 \%)$ & $31(25 \%)$ & 125 & \\
\hline $\begin{array}{r}\text { Levels of CO } \\
\left(\mathrm{mg} / \mathrm{m}^{3} \text {. median. IQR) }\right.\end{array}$ & No data & $\begin{array}{c}8.5 \\
(3.7-16.5)\end{array}$ & $\begin{array}{c}9.4 \\
(4.9-20.3)\end{array}$ & $\begin{array}{c}5.9 \\
(3-14.5)\end{array}$ & $\begin{array}{c}10 \\
(5.5-21.2)\end{array}$ & $\begin{array}{c}8.5 \\
(4-18.3)\end{array}$ & $<0.001$ \\
\hline $\begin{array}{r}\text { Levels of } \mathrm{CO}_{2} \\
\left(\mathrm{mg} / \mathrm{m}^{3} . \text { median. IQR) }\right.\end{array}$ & No data & $\begin{array}{c}839 \\
(749-961)\end{array}$ & $\begin{array}{c}814 \\
(742-920)\end{array}$ & $\begin{array}{c}774 \\
(724-846)\end{array}$ & $\begin{array}{c}810 \\
(734-941)\end{array}$ & $\begin{array}{c}801 \\
(740-917)\end{array}$ & $<0.001$ \\
\hline $\begin{array}{r}\text { Levels of TSP } \\
\left(\mathrm{mg} / \mathrm{m}^{3} \text {. median. IQR) }\right.\end{array}$ & $\begin{array}{c}466 \\
(370-888)\end{array}$ & $\begin{array}{c}295 \\
(79-853)\end{array}$ & $\begin{array}{c}800 \\
(231-1519)\end{array}$ & $\begin{array}{c}429 \\
(147-1182)\end{array}$ & $\begin{array}{c}1.384 \\
(557-3110)\end{array}$ & $\begin{array}{c}550 \\
(195-1444)\end{array}$ & $<0.001$ \\
\hline
\end{tabular}

$\mathrm{CO}=$ carbon monoxide. $\mathrm{CO}_{2}=$ carbon dioxide. $\mathrm{TSP}=$ total suspended particles. IQR=inter quartile range

*P-values refer to the difference between the five compared villages. tested with Chi-squared test for categorica variables and with the Kruskal-Walis test for medians 
Significantly higher levels of CO were measured in houses with burning fire (median 9.4, IQR: 4.7-20), as compared to houses with kindling fire - i.e. emitting visible smoke but not flame (7.4, IQR: 3.9-16.5) or dead fire (median 0.9, IQR: 0.3-1.1). The same trend was observed in the case of $\mathrm{CO} 2$ concentrations: burning fire median of 833 (IQR: 759-943), kindling fire me- dian 761 (IQR: 710-837) and dead fire median 704 $(\mathrm{IQR}=698-729)$. However, the highest levels of TSP were observed in houses where the fire was kindling (median 0.69, IQR: 0.23-1.81), compared with cases of burning fire (median of 0.58, IQR: 0.19-1.45) and dead fire (median 0.29, IQR: 0.06-0.38). These comparisons are presented in Figure 1.

Figure 1: Median levels of $\mathrm{CO}, \mathrm{CO}_{2}$ and TSP in houses with burning, kindling and dead fire
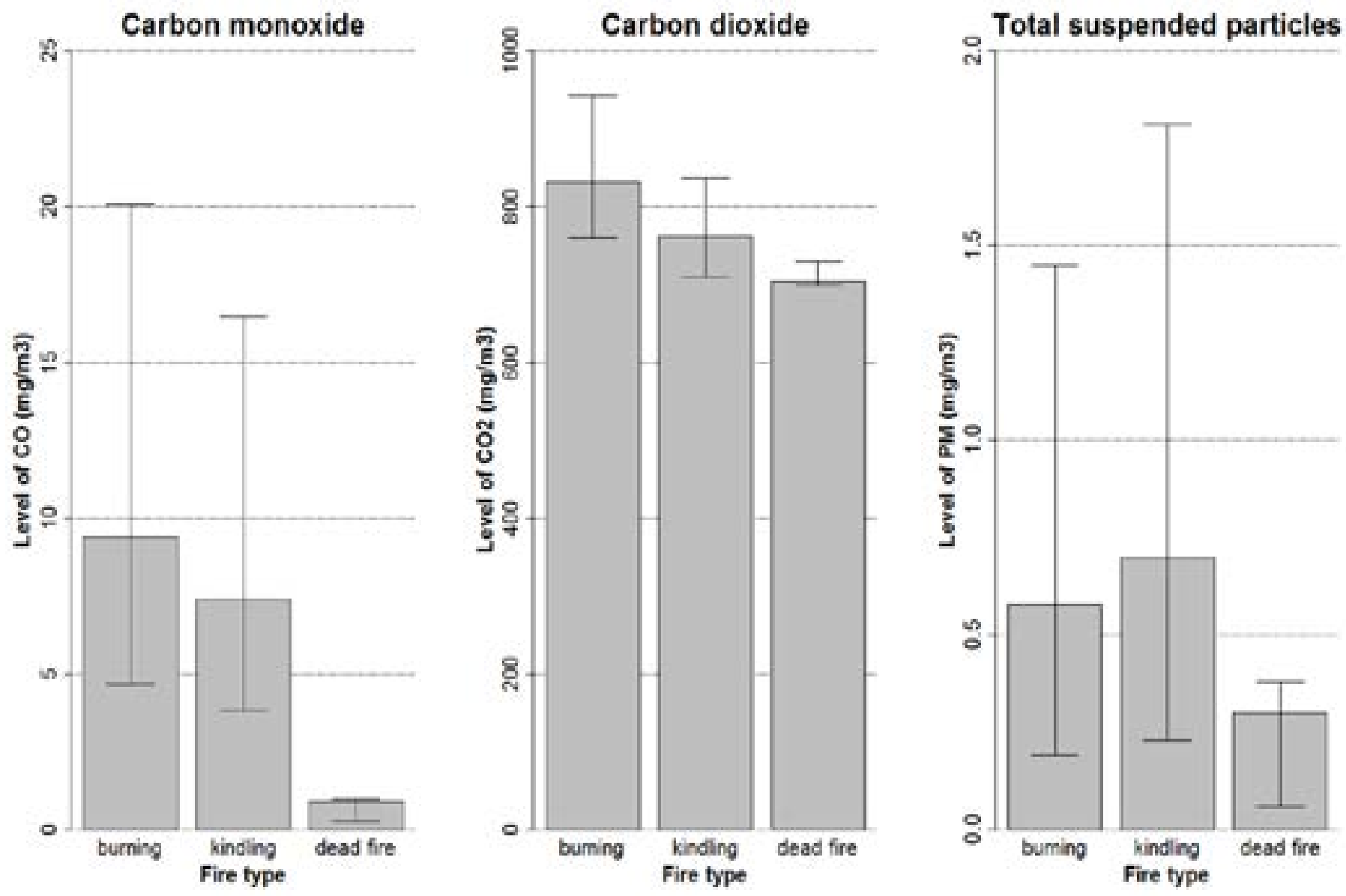

$\mathrm{CO}=$ carbon monoxide, $\mathrm{CO}_{2}=$ carbon dioxide, $\mathrm{TSP}=$ total suspended particles

Prevalence of respiratory illness, or the symptoms thereof, is presented in Table 3. A simple spirometrical screening examination was conducted in 155 respondents. Severe obstructive dysfunction was observed in
$28 \%$, mild obstructive dysfunction in $14 \%$ and in $40 \%$ of cases mild restrictive dysfunction was present. Overall, $83 \%$ of examinees showed a sub-optimal lung function to some degree. 
Table 3: Assessment of respiratory symptoms among the interviewed inhabitants of the sampled houses

\begin{tabular}{|c|c|c|c|c|c|c|c|c|c|c|c|c|c|}
\hline & \multicolumn{2}{|c|}{ Lukore } & \multicolumn{2}{|c|}{$\begin{array}{c}\text { Magawan } \\
\mathrm{i}\end{array}$} & \multicolumn{2}{|c|}{$\begin{array}{c}\text { Mwalupham } \\
\text { ba }\end{array}$} & \multicolumn{2}{|c|}{$\begin{array}{c}\text { Shimba } \\
\text { Hills }\end{array}$} & \multicolumn{2}{|c|}{ Waa } & \multicolumn{2}{|c|}{ Total } & \multirow[t]{2}{*}{$\begin{array}{c}\text { P- } \\
\text { value* }\end{array}$} \\
\hline & $\mathbf{N}$ & $\%$ & $\mathbf{N}$ & $\%$ & $\mathbf{N}$ & $\%$ & $\mathbf{N}$ & $\%$ & $\mathbf{N}$ & $\%$ & $\mathbf{N}$ & $\%$ & \\
\hline Number of respondents & 22 & 13 & 29 & 17 & 23 & 13 & 57 & 33 & 41 & 24 & 172 & $\begin{array}{c}10 \\
0\end{array}$ & \\
\hline Cough present without sickness (N. \%) & 3 & 14 & 1 & 3 & 1 & 4 & 7 & 12 & 0 & 0 & 12 & 7 & 0.005 \\
\hline \multicolumn{14}{|l|}{ Presence of respiratory disease during a year } \\
\hline 1-2 times per year & 9 & 50 & 8 & 28 & 13 & 59 & 31 & 57 & 30 & 73 & 91 & 56 & \multirow{3}{*}{0.046} \\
\hline 3-5 times per year & 7 & 39 & 15 & 54 & 8 & 36 & 20 & 37 & 8 & 20 & 58 & 36 & \\
\hline More than 5 times per year & 2 & 11 & 5 & 18 & 1 & 5 & 3 & 6 & 3 & 7 & 14 & 8 & \\
\hline $\begin{array}{l}\text { Presence of chronic respiratory sickness } \\
\text { (N. \% Yes) }\end{array}$ & 1 & 20 & 5 & 23 & 0 & 0 & 3 & 13 & 5 & 16 & 11 & 6 & 0.008 \\
\hline \multicolumn{14}{|l|}{ Prevalence of smoking } \\
\hline No never & 11 & 69 & 27 & 93 & 11 & 100 & 46 & 92 & 38 & 93 & 133 & 90 & \multirow{2}{*}{0.097} \\
\hline Yes. current or past smoker & 5 & 31 & 2 & 7 & 0 & 0 & 3 & 6 & 3 & 7 & 14 & 10 & \\
\hline \multicolumn{14}{|l|}{ Respiratory function determined by spirometry } \\
\hline Severe obstructive & 2 & 10 & 7 & 26 & 8 & 38 & 6 & 11 & 20 & 61 & 43 & 28 & \multirow{5}{*}{0.011} \\
\hline Severe restrictive & 0 & 0 & 0 & 0 & 0 & 0 & 2 & 4 & 0 & 0 & 2 & 1 & \\
\hline Other (milder obstructive) & 1 & 5 & 4 & 14 & 1 & 5 & 8 & 15 & 7 & 21 & 21 & 14 & \\
\hline Other (milder restrictive) & 12 & 57 & 8 & 30 & 12 & 57 & 26 & 49 & 4 & 12 & 62 & 40 & \\
\hline Normal & 6 & 28 & 8 & 30 & 0 & 0 & 11 & 21 & 2 & 6 & 27 & 17 & \\
\hline \multicolumn{14}{|l|}{ Respiratory disease among children $<5$ years } \\
\hline $1-2$ times per year & 6 & 55 & 9 & 38 & 8 & 38 & 8 & 44 & 9 & 64 & 40 & 45 & \multirow{3}{*}{0.159} \\
\hline 3-5 times per year & 3 & 27 & 14 & 58 & 9 & 43 & 10 & 56 & 3 & 22 & 39 & 44 & \\
\hline More than 5 times per year & 2 & 18 & 1 & 4 & 4 & 19 & 0 & 0 & 2 & 14 & 9 & 11 & \\
\hline Gender (N. \% female) & 12 & 54 & 24 & 83 & 21 & 91 & 37 & 65 & 31 & 76 & 125 & 73 & 0.025 \\
\hline Children $<18$ years & 1 & 5 & 0 & 0 & 0 & 0 & 3 & 5 & 2 & 5 & 6 & 4 & 0.722 \\
\hline Age (Median. IQR) & & & & & & & & & & & $\begin{array}{r}38 \\
(25.3- \\
\end{array}$ & & 0.881 \\
\hline
\end{tabular}

*P-values refer to the difference between the five compared villages. tested with Chi-squared test for categorical variables and with the Kruskal-Wlis test for medians

IQR=inter quartile range

A total of 172 respondents were interviewed using the respiratory questionnaire after an oral consent to participate. Three quarters of them were female. Over half of the respondents reported a respiratory sickness 1-2 times a year and over one third reported such problems 3-5 times a year. A total of 11 respondents (6\%) reported a chronic respiratory sickness (asthma or COPD). Only $10 \%$ of the interviewees were current or past smokers.

\section{Discussion}

This study evaluated the biomass related indoor air pollution on a sample of 125 rural households in Kwale region of Kenya and presents an analysis of exposure levels to their inhabitants. We also present an estimation of the prevalence of respiratory health symptoms among the inhabitants of the same houses. The study used simple tools and methods and involved local au- thorities and community members. Using such simple methods we confirmed the findings of previous studies from other regions of Africa that indoor pollution from use of biomass remains a significant public health hazard in this part of the world which requires attention. The findings of this study present a good starting point for more detailed investigations in this field and for planninginterventions.

\section{Indoor air quality}

During a series of short periods of sampling, the median levels of $\mathrm{CO}$ in the monitored houses ranged from 5.9 (IQR: $3-14.5)$ to $10(5.5-21.2) \mathrm{mg} / \mathrm{m}^{3}$. A study of the $\mathrm{WHO}^{5}$ summarized that in the settings similar to ours the 24 hour concentrations of $\mathrm{CO}$ ranged from 2.4-57 mg/ $\mathrm{m}^{3}$ and concentrations during stove use from $11.4-570+\mathrm{mg} / \mathrm{m}^{3}$; our results are therefore comparable to other studies. The safe levels of $\mathrm{CO}$ are set 
by the $\mathrm{WHO}^{20}$ and USEPA ${ }^{21}$ to $10 \mathrm{mg} / \mathrm{m}^{3}$ for an 8 hour average. Given the range of concentrations measured, and that the median time of fire use reported in the monitored houses was 6 hours (IQR 3-6), it is very likely that this threshold could be exceeded in some cases. Based on our measurements the median level of TSP for all houses was $550 \mu \mathrm{g} / \mathrm{m}^{3}$ (IQR 195-1,444) with medians for villages ranging from 295 (IQR 79-853) to 1,384 (IQR $557-3,110) \mu \mathrm{g} / \mathrm{m}^{3}$. A limitation of this study is that it was not possible to sample TSP fractions such as PM2.5 or PM10, which would have given more information concerning the potential risk posed by these levels of TSP. However, published guidelines for air quality ${ }^{24}$ suggest that concentrations of PM10 as low as $10 \mu \mathrm{g} / \mathrm{m}^{3}$ are associated with excess health risk, and the US EPA considers environments with PM10 levels exceeding $55.5 \mu \mathrm{g} / \mathrm{m} 3$ as being unhealthy ${ }^{21}$. Given that studies analysing smoke composition in laboratory settings conclude that $69 \%$ of the particles form wood burning are of sizes below $0.3 \mu \mathrm{m}$ and $8 \%$ of the total mass of particles are of size larger than $5 \mu \mathrm{m}^{22,23}$, it is very likely that a TSP measurement of $550 \mu \mathrm{g} / \mathrm{m}^{3}$ could contain unhealthy levels of particles in the PM2.5 and/or PM10 fractions. Further research work might attempt to discriminate these particulate fractions in the same conditions in order to give a more accurate estimate of the public health risk posed.

We also compared the levels of pollutants in cases of burning, kindling and dead fire. In case of $\mathrm{CO}$ and $\mathrm{CO}_{2}$ the concentrations were highest when flames were present and in case of TSP the levels peaked when the fire was kindling (meaning emitting smoke but without visible flames). It appears that when flames are not present the combustion of material is incomplete, producing a larger quantity of smoke, and thus the number of particles emitted increases as well. This phenomena warrants for further research that could confirm this or bring alternative explanations.

\section{The indicators of pulmonary health}

The evidence on the health effects of exposures to pollutants from biomass use is relatively well documented and indicates a large scale public health problem. A review on this topic concluded that the evidence in the case of the two most important conditions (Acute upper respiratory infections and COPD) is compelling and suggest causality to biomass related pollutants ${ }^{2}$. According to another review ${ }^{10}$ women using biomass as cooking fuel are three times more likely to suffer COPD than women using LPG or other cleaner fuels and ex- posed children less than five years are at increased risk of pneumonia. Another review ${ }^{25}$ suggests that there is an association between indoor air pollution and tuberculosis.

A spirometrical screening examination and a verbal, interviewer-led questionnaire were used to estimate the respiratory health in our sample. All respondents reported lower respiratory infections at least once a year and $44 \%(\mathrm{~N}=72)$ of them reported such problems more than 3 times per year. It must be noted that thisdata is self-reported and has not been verified against any medical records. However, this questionnaire was specifically designed and pilot tested with the aim of minimising difficulties in comprehension of standard questionnaires, which have previously been reported, for example in the use of the ATS-DLD- $78^{17}$ or the St. George $^{18}$ respiratory questionnaire.

The spirometrical screening showed normal function only in $17 \% \quad(\mathrm{~N}=27)$ of the examinees. However, a causal relationship between the measured levels of indoor smoke and poor lung function cannot be asserted: Although the spirometrical exams were overseen by an experienced technician it can be difficult to explain the procedure to the participants and in a number of cases the test may have been incompletely performed. Furthermore, a sampling bias is likely for two reasons:

1) the examinees were mostly women who typically prepare the food, which means that we can assume higher exposure compared to other family members;

2) other subjects included elderly members of the household, in whom higher rates of respiratory dysfunction could expected due to their age. Due to these facts the prevalence of respiratory dysfunction found in our sample could be considerably higher than that found in the general population in the area (that would include young men being at work at the time of the study, and children attending school). Owing to the noted limitations, we do not draw any conclusions regarding indoor smoke as a causative agent in COPD from the research presented here. Nonetheless the presented data is indicative of poor levels of lung health which, taken in conjunction with the established high burden of respiratory infection locally may be useful for planning of further studies and as a basic description of the studied problem.

There have also been indications of relationships between biomass-related pollution and other health effects including low birth weight, ischaemic heart dis- 
ease, nasopharyngeal and laryngeal cancer or lung cancer $^{10,12,26}$. The evidence for these relationships is of varying quality, owing to methodological difficulties including the need for randomisation and/or a proper control group, or adjustment for confounding factors such as socio-economic status, behavioural factors and others. Some authors ${ }^{27}$ argue that the homogenous distribution of the exposure in the affected area as such, may also hinder the possibility of detection of causal relationships. Again, the data we present may stimulate further research into local health problems that could be exacerbated by smoke inhalation.

\section{Short term monitoring as a method}

The study used a simple methodology and simple tools to conduct a relatively quick, cheap and comprehensive assessment of biomass-related indoor air pollution and its health impacts in the target population. Rather than focusing on the evaluation of causal relationships the emphasis was put on designing a simple methodology which could potentially be used by local authorities and community workers. This endeavour is in line with the suggestions of most research or interventions studies in this field who emphasize the role of community members and local authorities in successful implementation of intervention strategies ${ }^{5,6,10,28}$.

Representatives of the DPHO as well as community members (community workers) actively contributed to field work within this study which creates ground for local-authorities-driven routine monitoring. Such routine monitoring could be seen as an integral part of a) creating a comprehensive assessment of the causes, drivers, consequences and possible solutions to the problem of biomass-related indoor air pollution; b) educating the community on the harmful effects of biomass pollution on health; c) designing and implementing community-accepted and thus sustainable interventions.

\section{Limitations to the study and generalizability}

Limitations such as the challenges of comprehending and complying with unfamiliar questionnaires and medical equipment have been noted above. Additionally we would note that the study did not use long term continuous sampling of indoor air; this was not possible for practical reasons such as a lack of electricity outlets in the sampled houses. This may present a limitation as the variation of concentrations throughout the day could not be measured. Furthermore, the equipment used only allowed sampling of TSP levels without filter- ing the respirable fraction. Future work might attempt to sample particular smoke fractions which are known to be of health significance. These factors could limit the validity of our findings. Due to the relatively short sampling time (20 minutes) and variability of the daily exposure due to behaviours of the inhabitants, and other factors such as type of wood used, time of the fire burning, variability in the composition of the PM (as to size of particles), we are not able to define continuous daily exposures. Our study was designed to describe the situation in the specific setting of rural coastal Kenya and to provide contemporary quantified information to researchers and to local health and public health authorities. More detailed exposure assessment, or alternative study designs may be required in order to address causal considerations. The findings presented here may help to inform the design of such studies. The outdoor concentrations of dust particles could contribute to the overall levels of TSP measured indoors. Due to limitations as to availability of equipment we were unable to perform simultaneous indoor-outdoor samplings. Although this may be considered a limitation of our methods we do not expect significant influences for three reasons:

1) the weather conditions during all monitoring days were similar;

2) the time of measurements during the day was the same for all days;

3) most of the kitchens had none or small windows, and thus the connection of the indoor and outdoor environments was limited.

Consecutive selection of households and respondents was applied without randomization and this may bias our finding towards the selection of more central and/or accessible residences. However, a uniformity in house characteristics and behaviour (as to cooking fuel used and style of cooking) was observed and therefore such a bias is unlikely to be of practical relevance. Our data is not adequate to draw conclusions concerning causal relationships between the exposure and health effects under study, as has been described. The spirometrical examinations reported in this paper should be considered only indicative of the actual situation in the population under study:

1) the equipment used was not intended to establish a clinical diagnosis;

2) we report difficulties in understanding the procedure by the participants;

3) sampling bias could have increased the observed prevalence of symptoms of poor lung function. There- 
fore, readers are warranted to use this information with caution; we do not claim to establish any type of causal relationship between exposures and health outcomes, but the prevalence of symptoms and associated high levels of airborne pollution may merit further research to investigate cause.

\section{Conclusions}

We present a study of the total levels of indoor smoke that can be measured in association with typical local housing design and cooking practices in a rural African setting.

We believe that our study presents a practical and simple methodology to assess objectively the scale of the problem of indoor air pollution, and an indication of the ongoing need to address the public health consequences of the use of biomass fuels, backed up by questionnaire and spirometry data pointing to poor lung health among the houses' residents. Our results suggest that biomass-fuel related indoor air pollution remains a potential public health problem in rural regions of Kwale in Kenya. Our findings create grounds for more detailed investigations of the problem and suggest there is merit in exploring community based interventions, for example in the provision of cleaner and more sustainable cooking methods.

\section{Acknowledgements}

We are grateful to the great team of the Kwale district office of Public Health in Kwale and in the dispensaries where this study was conducted. Without their eager help, enthusiasm and involvement this study could not be conducted. We would like to thank the Ministry of Public Health and Sanitation, the Ministry of Health and the hospital in Kwale for their support for this study. The team of the Kwale Health Project, especially Adela Bodova were helpful with logistical issues. Funding was provided from an institutional grant of the Faculty of Health Sciences and Social Work of the Trnava University in Slovakia. The work of Dr. Majdan was partly supported by a grant received from the Trnava University (grant No. 12/TU/2014).

\section{Conflict of interest}

There are no conflicts of interests.

\section{Funding}

Funding was provided from an institutional grant of the Faculty of Health Sciences and Social Work of the Trnava University in Slovakia.

\section{References}

1. Ezzati M, Kammen DM. The health impacts of exposure to indoor air pollution from solid fuels in developing countries: knowledge, gaps, and data needs. Environ Health Perspect. 2002;110(11):1057-68.

2. Bruce N, Perez-Padilla R, Albalak R. Indoor air pollution in developing countries: a major environmental and public health challenge. Bulletin of the World Health Organization. 2000;78(9):1078-92.

3. Sundell J. On the history of indoor air quality and health. Indoor air. 2004;14 Suppl 7:51-8.

4. World Resources Institute U, UNDP, World Bank. 1998-99 PubMed world resources: a guide to the global environment.: Oxford University Press; 1998.

5. Bruce N, Perez-Padilla R, Albalak R. The health effects of indoor air pollution exposure in developing countries. Geneva: Worl Health Organization; 2002.

6. Smith KR. Indoor air pollution in developing countries: recommendations for research. Indoor air. 2002;12(3):198 PubMed -207.

7. Naeher LP, Brauer M, Lipsett M, Zelikoff JT, Simpson CD, Koenig JQ, et al. Woodsmoke health effects: a review. Inhalation toxicology. 2007;19(1):67-106.

8. Manish A. Desai SM, Kirk R. Smith. Indoor smoke from solid fuels: Assessing the environmental burden of disease at national and local levels. Geneva: World Health Organization; 2004.

9. Fullerton DG, Bruce N, Gordon SB. Indoor air pollution from biomass fuel smoke is a major health concern in the developing world. Transactions of the Royal Society of Tropical Medicine and Hygiene. 2008;102(9):843-51.

10. Kim KH, Jahan SA, Kabir E. A review of diseases associated with household air pollution due to the use of biomass fuels. Journal of hazardous materials. 2011;192(2):425-31.

11. Kodgule R, Salvi S. Exposure to biomass smoke as a cause for airway disease in women and children. Current opinion in allergy and clinical immunology. 2012;12(1):82-90.

12. Po JY, FitzGerald JM, Carlsten C. Respiratory disease associated with solid biomass fuel exposure in rural women and children: systematic review and meta-analysis. Thorax. 2011;66(3):232 PubMed -9.

13. Ezzati M, Kammen DM. Quantifying the effects of exposure to indoor air pollution from biomass combustion on acute respiratory infections in developing countries. Environ Health Perspect. 2001;109(5):481-8.

14. Romieu I, Riojas-Rodriguez H, Marron-Mares AT, Schilmann A, Perez-Padilla R, Masera O. Improved bi- 
omass stove intervention in rural Mexico: impact on the respiratory health of women. American journal of respiratory and critical care medicine. 2009;180(7):649-56.

15. Casella. Casella Microdust Pro - real time dust monitor http://www.casellameasurement.com/am_wp_realtime_dust_voc.htm2013 [cited 2013 18.june 2013].

16. Solutions GS. IAQ indoor air quality monitor http:// www.wolfsense.com/directsense-iaq-indoor-air-quality-monitor.html2013 [cited 2013 18.June].

17. Lebowitz MD, Knudson RJ, Burrows B. Tucson epidemiologic study of obstructive lung diseases. I: Methodology and prevalence of disease. American journal of epidemiology. 1975;102(2):137-52.

18. Jones PW, Quirk FH, Baveystock CM. The St George's Respiratory Questionnaire. Respiratory medicine. 1991;85 Suppl B:25-31; discussion 3-7.

19. SpiroPro. SpiroPro Spirometer http://www.nagelnetwork.com/inexspir.htm2013 [cited 201318 June]. 20. WHO. WHO guidelines for indoor air quality: selected pollutants. Geneva2010.

21. USEPA. Revisions to the National Ambient Air Quality Standards for Particle Pollution. Federal Register July 18. 1997;62(138).
22. Ch. Hueglin CG, S. Künzel, and H. Burtscher. Characterization of Wood Combustion Particles: Morphology, Mobility, and Photoelectric Activity. Environmental Science and Technology. 1997;31(12):3439-47.

23. David V. Sandberg REM. Particle sizes in slash fire smoke. USDA Forest service Research papers. 1975(PNW-199).

24. WHO. Air Quality Guidelines for Europe World Health Organization Regional Office for Europe. Copenhagen: WHO; 1999.

25. Sumpter C, Chandramohan D. Systematic review and meta-analysis of the associations between indoor air pollution and tuberculosis. Tropical medicine $\&$ international health : TM \& IH. 2013;18(1):101 PubMed $-8$.

26. Lim WY, Seow A. Biomass fuels and lung cancer. Respirology. 2012;17(1):20 PubMed -31.

27. Boleij JS, Brunekreef B. Domestic pollution as a factor causing respiratory healtheffects. Chest. 1989;96(3 PubMed Suppl):368S-72S.

28. Naeher LP. Biomass-fueled intervention stoves in the developing world: potential and challenges. American journal of respiratory and critical care medicine. 2009;180(7):586-7. 